results in disagreement about what is morally acceptable and because there is no consensus on the best theories and methods for determining this. Bloch \& Green (2006) address this problem and suggest a solution by proposing the combination of two established ethical approaches - principlism and care ethics. Their attempt is laudable but the result may be lacking.

Perhaps the most important flaw is that care ethics is riddled with problems (Rudnick, 2001) that may not be adequately resolved by combining care ethics and principlism. For instance, care ethics encourages an overly paternalistic approach by practitioners, which is illustrated by the parent-child model of physician-patient interaction, as presented by many care ethics proponents. In addition, care ethics may be philosophically redundant, as it may be reducible to more veteran ethical approaches such as virtue ethics and casuistry (case-based ethics), which are also notoriously problematic.

If care ethics is not satisfactory as part of an ethical framework for psychiatry, what could be a better alternative? A promising and relatively novel approach is dialogical ethics, which may need to be combined with justice or fairness considerations (Rudnick, 2002). This approach accepts moral pluralism but utilises sound procedures and processes of dialogue among all parties involved to address ethical problems satisfactorily. Dialogical ethics may be well suited to highlighting and addressing some of the more special problems of psychiatric ethics. For instance, dialogue with patients may sometimes pose special challenges in psychiatry, as it requires particular communication skills and cognitive abilities that may sometimes be deficient in people with mental illness. This deficiency could be addressed by remediation and accommodation strategies, as well as by substitute decision-making (which would also be required to engage in dialogue to address the given ethical problem). Be that as it may, a reconsideration of the ethical framework of psychiatry is needed.

Bloch, S. \& Green, S. A. (2006) An ethical framework for psychiatry. British Journal of Psychiatry, 188, 7-12.

Rudnick, A. (200I) A meta-ethical critique of care ethics. Theoretical Medicine and Bioethics, 22, 505-517.

Rudnick, A. (2002) The ground of dialogical bioethics. Health Care Analysis, 10, 391-402.

A. Rudnick Department of Psychiatry and

Philosophy, University of Western Ontario, and
Regional Mental Health Care, 850 Highbury Avenue, London, Ontario N6A 4HI, Canada. Email: arudnic2@uwo.ca

doi: 10.I192/bjp.189.1.83b

I found the philosophical discussions of Bloch \& Green (2006) interesting, without necessarily revealing anything new. However, I was deeply concerned by the case used as an illustration. It appeared to reflect a rather paternalistic, single-professional, single-agency approach to child protection. Clinically this perspective can lead to serious mistakes. As named doctor for child protection for the Leicestershire Partnership NHS Trust I train other staff to seek advice from me and from the named nurse. There was no mention by Bloch \& Green of statutory duties of care to the child. The fundamental principle of paramountcy was not mentioned. It was identified that with a mother with psychosis there was a significant risk of harm to the young child. Once this is identified, the children's social services department should be notified (Department of Health, 1999), and should take the lead role in carrying out Section 47 child protection enquiries. All agencies have a duty to assist in collating and sharing all relevant information, to update on the situation and assist in monitoring the child and providing additional support. Reder et al (1993) give many examples where information is known to one or two individuals in single agencies who fail to share it, resulting in the omission of any child protection plan. If anything seriously untoward were to happen to the baby, a thorough case review would be undertaken by the area child protection committee/local safeguarding board and a doctor could potentially be found negligent for failing to carry out child protection procedures. I wonder whether this highlights the need for many doctors to update their child protection training?

Bloch, S. \& Green, S. A. (2006) An ethical framework for psychiatry. British Journal of Psychiatry, 188, 7-12.

Department of Health (1999) Working Together to Safeguard Children: A Guide to Interagency Working to Safeguard and Promote the Welfare of Children. London: TSO (The Stationery Office).

Reder, P., Duncan, S. \& Gray, M. (1993) Beyond Blame: Child Abuse Tragedies Revisited. London: Routledge.

J. Bruce Brandon Mental Health Unit, Leicester General Hospital, Gwendolen Road, Leicester LE5 4PW, UK

Email: Janet.Bruce@leicspost.nhs.uk doi: 10.I192/bjp.I89.1.84

\section{Job satisfaction of mental health social workers}

Evans et al (2006) address major issues concerning mental health social workers, who are an important part of the multidisciplinary team. Although a remarkable paper, I would like to raise a few points regarding the methodology.

First, a single-item rating scale was used to measure job satisfaction, which I consider a multidimensional construct. It can be influenced by a variety of factors and should have been measured using scales such as the Job Descriptive Index (JDI; Balzer et al, 1997) or the WarrCook-Wall scale (Warr et al, 1979). The JDI assesses the amount of work in the job, current pay, opportunities for promotion, supervision and co-workers. The Warr-Cook-Wall questionnaire covers overall job satisfaction and satisfaction with nine aspects of work, each rated on a seven-point Likert scale with higher scores representing greater satisfaction.

Second, there is no mention of the reliability or validity of scales used to measure burnout and job satisfaction. In addition, the adjusted response rate is only $49 \%$ and the profile of non-responders is not included to clarify responder bias. Moreover, stepwise multiple regression would have been more useful than linear regression to investigate the relationship between several independent variables and a dependent variable.

Notwithstanding these limitations, this paper should be an eye-opener to employers regarding the needs of mental health social workers.

Balzer, W. K., Kihm, J. A., Smith, P. C., et al (1997) User's Manual for the Job Descriptive Index (JDI) and the job In General ( $/ \mid G)$ Scales. Bowling Green, $\mathrm{OH}$ : Department of Psychology, Bowling Green State University.

Evans, S., Huxley, P., Gately, C., et al (2006) Menta health, burnout and job satisfaction among ment health social workers in England and Wales. British Journal of Psychiatry, 188, 75-80.

Warr, P., Cook, J. \& Wall, T. (1979) Scales for the measurement of some work attitudes and aspects of psychological well-being. Journal of Occupational Psychology, 52, 129-148.

N. Kader MerseyCare NHS Trust, Park Lodge Hospital, Orphan Drive, Liverpool L6 7UN, UK. Email: nishakeem@gmail.com doi: 10.I192/bjp.189.I.84a

Authors' reply: We agree that job satisfaction is a multidimensional construct, and we measured several features of 